\title{
International Journal of Technology and Systems
} (IJTS)

\section{IMPLICATION OF GIS ON SUSTAINABLE URBAN PLANNING AND MANAGEMENT IN UGANDA}

\author{
PAMIREDDY SRILATHA REDDY (PHD)
}

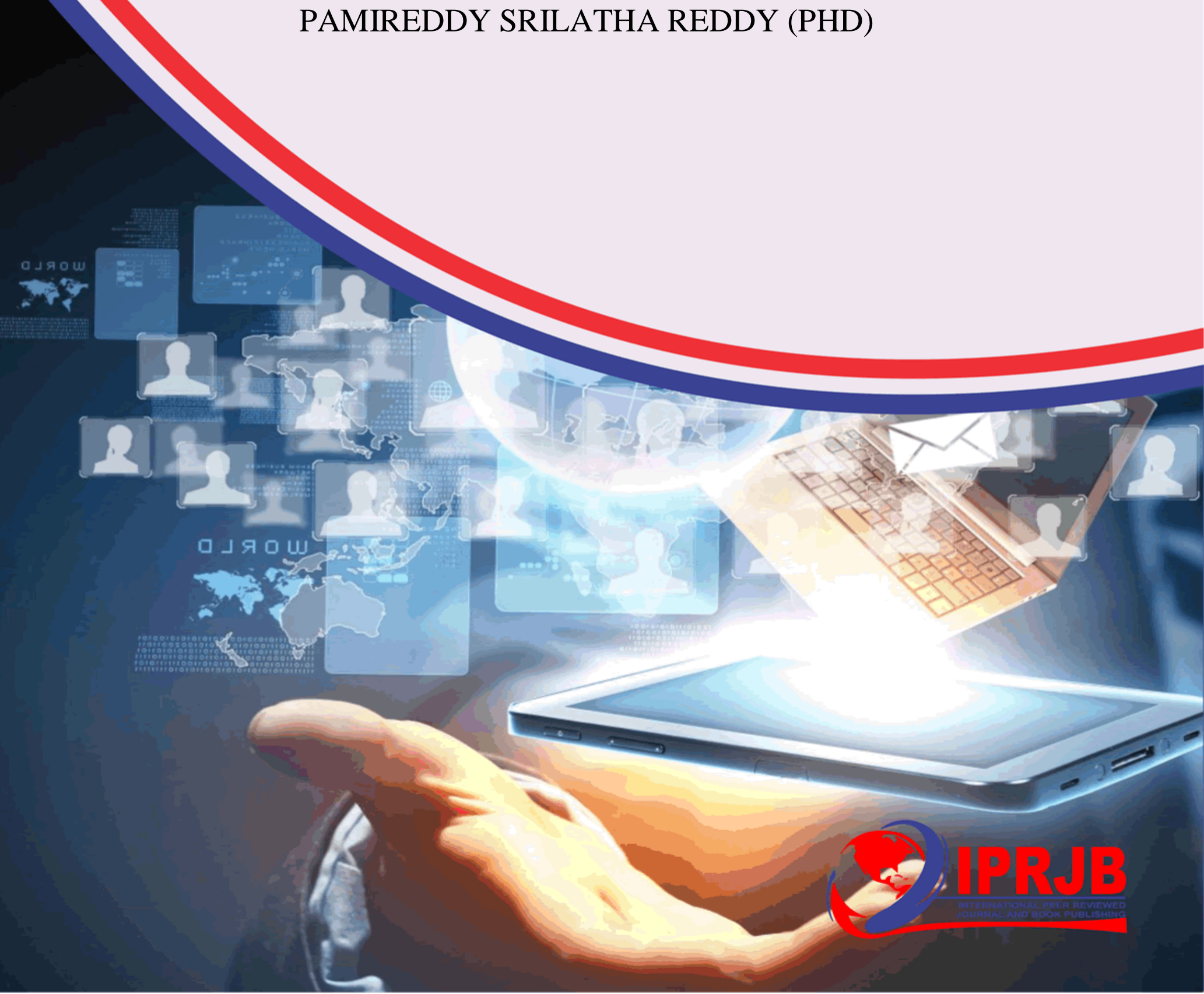




\title{
IMPLICATION OF GIS ON SUSTAINABLE URBAN PLANNING AND MANAGEMENT IN UGANDA
}

\author{
Pamireddy Srilatha Reddy (PhD) \\ Jawaharlal Nehru Technological University Hyderabad \\ Corresponding Author’s Email: srilathareddyug@gmail.com
}

\begin{abstract}
Purpose: The fundamental purpose of this study was to assess the implication of GIS on sustainable urban planning and management in Uganda, one of the East African countries.

Methodology: This study was a desk review research where documents were reviewed using a documentary checklist as the primary data collection instrument. Data was analyzed using content thematic analysis where emerging themes were identified and presented in a narrative form accompanied with quotation of texts from the documents where the identified themes emerged from.

Findings: This study found out that GIS contributes to sustainable urban planning and management through the following ways; analyzing the existing situation for adequate urban planning process; producing and maintaining geographical information which aids planning of urban areas and towns; providing quick access of data to planners and other stakeholders which eases the urban planning and management process; enabling planners to make effective, efficient and informed decision with regards to urban planning and management; enabling monitoring, evaluation and provision of feedback with regards to implementation of urban plans.

Unique contribution to theory, practice and policy: This study concludes that GIS has a positive implication on sustainable urban planning and management. This study also recommends that Governments of developing economies especially low income and middle income economies, Uganda not being exceptional should develop a strong data base for GIS systems so as to enable quick access to data by planners for effective and informed decision making in order to foster sustainable urban planning and management in low and middle income countries.
\end{abstract}

Keywords: GIS, Sustainable, Urban planning, Management, Demographics

\section{Introduction}

Developing effective urban planning strategies and monitoring their spatial impact requires morphological and functional land-use maps showing the ongoing urban growth processes (Van de Voorde, Jacquet \& Canters, 2011). Geographical Information system (GIS) is used to understand and solve urban problems, process of planning and management of urban regions (Maarseveen, Martinez \& Flacke, 2018). However, Uganda's urbanization and management has 
been happening amidst weak or in the absence of adequate geographical information system. As a consequence, Uganda's urbanization is characterized by the growth of unplanned cities with high rates of spatial expansion (sprawl) and unplanned growth, lack of integration between sectoral and spatial planning, inadequate provision of basic services, weak urban management capacity, congestion diseconomies, landscape being dominated by informal housing, slums and a deteriorating urban environment with significant fiscal constraints (World Bank, 2012). In addition, there is scanty literature and little attention has been paid to the implication of GIS on sustainable urban planning and management in Uganda. Uganda's urbanization and management has been happening amidst weak or in the absence of adequate geographical information systems. The high urban growth rate in Uganda estimated at $20 \%$ has not been properly planned and guided, characterized by organic growth of unplanned urban areas that are characterized by a weak urban economy, slums and informal settlements, weak urban governance and institutional coordination, inadequate urban infrastructure and services for that reason this study sought to examine the implication of GIS on sustainable urban planning and management. Since the early 1980s, there has been a marked increase in the installation of GIS in different levels and departments of urban and regional governments in the developed countries, notably of Europe (Bardon et al 1984; Campbell 1994) and North America (French and Wiggins 1990). With the further decrease in the price of computer hardware and software, the use of GIS has emerged in urban planning in the developing countries in the 1990s (Yeh 1991). GIS is increasingly accessible to planners and is now an important tool for urban planning in developed and developing countries alike.Therefore, this article intends to shed light about the implication of GIS on sustainable urban planning and management in Uganda. This paper is structured into the background to the study, statement of the problem, research objective, research methodology, findings, conclusion and recommendations.

\section{Background of the study}

The world is becoming increasingly urbanized. Since 2007, more than half the world's population has been living in cities, and that share is projected to rise to 60 per cent by 2030 (United Nation, 2021). Cities and metropolitan areas are powerhouses of economic growth contributing about 60 per cent of global GDP. However, globally rapid urbanization is resulting in a growing number of slum dwellers, inadequate and overburdened infrastructure and services (such as waste collection and water and sanitation systems, roads and transport), worsening air pollution and unplanned urban sprawl (United Nation, 2021).

In Africa, by 2030, the annual average rate of urban growth is expected to be $3.6 \%$ in SubSaharan Africa (Van de Voorde, Jacquet \& Canters, 2011). A rapidly urbanizing region, projected estimates indicate that by 2025 approximately half of the African population will be urban (UN-Habitat, 2008/9). Furthermore, according to the UN-Habitat State of the World's Cities Report, 2006/7, rapid urbanization in Africa has occurred in the absence of a stable 
economic base though recent economic experiences show averagely high GPD rates for various countries. With chronic poverty widely prevalent, urbanization and slum formation are inextricably linked (UN-Habitat, 2007). Compounding this situation statistics in 2012 indicate that slums in Africa grew at a rate of 4.53 per cent per annum while overall urban growth rates were 4.58 per cent almost leveling the urban growth is thus synonym to slum growth (Lwasa \& Kinuthia-Njenga, 2012). With an average annual rate of 1.4 percent between 2010 and 2015, Africa is the second-fastest urbanizing continent, second only to Asia. Yet, urbanization in Africa has failed to bring about inclusive growth which, in turn, has resulted in proliferation of slums, urban poverty and rising inequality (Sow, 2015). Furthermore, much of the Urbanization in Africa is characterized by unplanned and unregulated growth exacerbated by weak planning institutions (Pieterse \& Parnell, 2014).

Uganda just like any other Sub-Saharan African country is experiencing a high rate of urbanization estimated at 5.2\% per annum. About 20\% of Uganda's population lives in urban areas and it is projected by 2050, about half of Uganda's population will be living in urban areas (Ministry of Land, Housing \& Urban Development, 2017). Most of this growth has been in secondary towns such as Hoima $-10.7 \%$, Mbarara - 8.6\%, and Mukono - 10.4\%, (Uganda Bureau of Statistics UBOS, 2014). The Greater Kampala Metropolitan Area (GKMA) has the highest urban population representing over $50 \%$ of Uganda's total urban dwellers. However, Uganda's rapid urbanization has not been matched by similar growth in the capacity of local authorities to plan and manage urban growth which has led to the proliferation of slums and informal settlements characterized by poverty and poor living conditions with substandard housing, overcrowding and limited access to services (Ministry of Land, Housing \& Urban Development, 2017). Within this context while the secondary towns are being elevated to city status, unless they are managed properly they will grow into large unplanned settlements over time. Uganda has the rare opportunity to proactively manage urbanization within the secondary towns and newly created cities to ensure a better future for its residents. Thus, this study examines the implication of geographical information system on sustainable urban planning and management in Uganda.

\section{Statement of the problem}

GIS has been noted to facilitate urban planning and management through providing planners with tools to design, analyze existing situation and map their neighborhoods and cities to aid in sustainable urban planning and management (Shimonti, 2018: Hegazy \& Kaloop, 2015). However, and despite the adoption of GIS system in the urban planning and management of secondary towns and cities in Uganda such as Kampala (Kampala Capital City Authority, 2021: Hemerijckx, Emelen, Rymenants, Davis, Verburg, Lwasa \& Rompaey, 2020: Ofori-Amoah, 2009), the high urban growth rate in Uganda estimated at $20 \%$ has not been proper planned and guided (Mbabazi \& Atukunda, 2020). This has led to the organic growth of unplanned urban 
areas that are characterized by a weak urban economy, slums and informal settlements, weak urban governance and institutional coordination, inadequate urban infrastructure and services, land-use disorder and uncontrolled urban sprawl, increasing environmental deterioration, inadequate urban investment and financing, delimitation of urban areas of jurisdiction and lack of integrated planning across jurisdictional boundaries. This has adversely affected the potential of the urban sector as an engine of economic development (Mbabazi \& Atukunda, 2020: MOLHUD, 2017). If the current situation continues to prevail, Uganda may not achieve its Vision 2040 and National Development Plan 3 which emphasize proper management of the urbanization process to bring about better urban systems that enhance productivity, livability and sustainability while releasing land for commercial agriculture for the Country to benefit and reap big from the urbanization process. In addition, this situation ought to cost Uganda success in achieving global agendas such as The New Urban Agenda and SDG 11 which emphasizes making cities inclusive, safe, resilient and sustainable. It is a midst this background that this study seeks to examine the implications of GIS on sustainable urban planning and management in Uganda.

\section{Objective of the study}

This study assessed the implication of GIS on sustainable urban planning and management in Uganda

\section{Literature Review}

There is an increasing realization of the need to use information communication technologies (ICT) such as Geographical Information Systems for various applications in Uganda and other developing countries. This is manifested by the various policies that governments continue to develop geared at mainstreaming ICT in government core activities. In Uganda for example, a new ministry of ICT was created to promote use of ICT in all government functions and most government departments are at various stages of developing platforms for providing eservices to the public, the investors and the business community (Musinguzi, 2012).

In accordance with Aibinu (2001) the importance of current data and information cannot be overemphasized for planning to be effective and efficient. Basic data and information is needed for the planning and development of the cities on the spectrum of the information needed for meeting the functions of government at that level. Indeed data and information have traditionally been the underlying principles in any development initiatives. Data are facts and information collected to improve the quality of decisions and actions. It is therefore not surprising that recently, much effort and resources have been concentrated by agencies and projects in developing countries on the collection, coalition, analysis, and interpretation of information and data necessary for their effective functioning. In recent times, there has been an increasing awareness of the role of information technology in achieving these tasks for overall societal 
advancement. Particularly, the development of geographic information system (G.I.S) that has revolutionized the collection, coalition, analysis and interpretation of data for planning and decision making process especially in urban and regional planning initiatives. This is because the data storage, updating, retrieving and manipulating capabilities of GIS have implications for developing strategies of urban management and planning for sustainability in the developmental process (Aibinu, 2001).

In general, application of GIS has the following advantages; Large quantities of data can be promptly updated than is otherwise possible, eliminates manual operations between information input and output on the other hand, helps in identifying, clarifying and addressing urban issues through a geographically differentiated approach, supports in producing, storing, and updating urban information for planning and management and helps to build broad based capacities in resource management (Morosini and Zucaro, 2019). The use of the GIS in urban planning does not depend solely on the development of new GIS software and hardware but has some considerations like the status and character of the organization, data, state-of-the-art of planning, and staff as important factors (Yeh, 2015).

Giving direction to city development that is in line with the social, environmental and economic dimensions of sustainability is one of the core tasks of spatial planning (Steinebach, 2009). Improving planning and management systems, as well as decision-making processes, is important if one is to address the relevant social and economic dimensions stressed. The role of urban planners has been changing to include the building of knowledge bases from a more participatory, stakeholder-based perspective, as well as relying on the inclusion of geographical information systems support for decision-making processes (Jankowski and Nyerges, 2001).

Nikuze, Sliuzas and Flacke (2018) posit that rapid urbanization and frequent natural disasters have substantially increased the number of urban households - especially poor households - that have to be relocated away from their homes and communities (Satiroglu and Choi, 2015). Urbanization in developing countries is associated with many challenges, among them poverty and viral growth of informal settlements, many of which are often exposed to various natural hazards (Manirakiza, 2014). Resettlement is one option for reducing the risk of natural disasters that is being adopted both before and after the occurrence of a disaster (Correa, Ramirez and Sanahuja, 2011). Governments and international agencies increasingly consider resettlement of vulnerable urban communities as a risk reduction strategy (Ibrahim et al., 2015). Disaster risk mitigation is an indispensable instrument for protecting people's lives and assets, as well as expanding national and local economies. Poorly executed resettlement may, however, induce loss of livelihood and increase the vulnerability and impoverishment of the displaced population (Nikuze et al., 2018).

Morosini and Zucaro (2019) affirm that this contribution pursues the line of thought of many engineers or architects, like Renzo Piano, who firmly believe in the need to transform cities 
without additional soil consumption, which means "re/build in the built environment", and proposes a 3D GIS-based methodology aimed at identifying the portions of the urban area most susceptible to transformation within already-urbanized areas, on the basis of the physical, builtup (height, land use, etc.) and context (shading areas, panoramic views, etc.) characteristics of the urban system. In particular, the proposed methodology intends to support local decision makers in detecting, among the existing buildings, those where new urban services might be introduced by intensifying infill practices, thus promoting a sustainable land management.

On the other hand sustainable development involves economic, social and environmental processes that are inherently spatial. These processes can hardly be understood without taking into account their spatial dimensions. GIS Science has been proven to offer theories, methods and applications to effectively support the following categories of tasks, which together find wide space for application to fulfill the principles of sustainable development as listed; producing and maintaining geographic information, supporting distributed access to information, solving spatial problems, supporting collaborative decision making, and supporting public participation (Campagna, 2006).

Bahaire and Elliot-White (2010) state that Geographical Information Systems (GIS) can be regarded as providing a tool box of techniques and technologies of wide applicability to the achievement of sustainable development. Spatial (environmental) data can be used to explore conflicts, examine impacts and assist decision-making. Impact assessment and simulation are increasingly important in development, and GIS can play a role in auditing environmental conditions, examining the suitability of locations for proposed developments, identifying conflicting interests and modeling relationships. Systematic evaluation of environmental impact is often hindered by information deficiencies but also tools for data integration, manipulation, visualization and analysis. GIS seems particularly suited to this task.

\section{Methodology}

This section presents the methods use in carrying out the research study. It highlights the nature of the study, data collection method and instrument, data analysis technique used.

\section{Nature of the study}

This study was a desk review research where secondary data were reviewed. The documents reviewed included; journal articles, reports from development partners, reports from Uganda Bureau of Statistics, Ministry of Lands, Housing \& Urban Development, gray literature, published and unpublished research work and reports. Qualitative research approach was used where documents were reviewed purposively according to the inclusion criteria of the study, which constituted all relevant materials with characteristics of the implication of GIS on sustainable urban planning and management that formed a basis of basis for inclusion in the on the implication of GIS on sustainable urban planning and management in Uganda. 
International Journal of Technology and Systems

ISSN 2518-881X (Online)

Vol.5, Issue 1, No.2, pp 15-27, 2021

WwW.iprjb.org

\section{Data collection method}

Documentary review method was used to collect data. The documentary method is described as the technique used to categorize, investigate, and interpret written documents whether in the private or public domain; it is the analysis of documents that contain information about the phenomenon under a study.

\section{Data collection instrument}

Data obtained from the documentary review were analyzed using inductive manual thematic content analysis where emerging themes from the different documents were identified and quotations of texts were also made from the documents reviewed.

\section{Data analysis}

Data obtained from the documentary review were analyzed using inductive manual thematic content analysis where emerging themes from the different documents were identified and quotations of texts were also made from the documents reviewed.

\section{Findings}

From the literature reviewed, the following emerged as themes with regards to the implication of GIS on sustainable urban planning and management

Identified themes and frequency of their occurrence

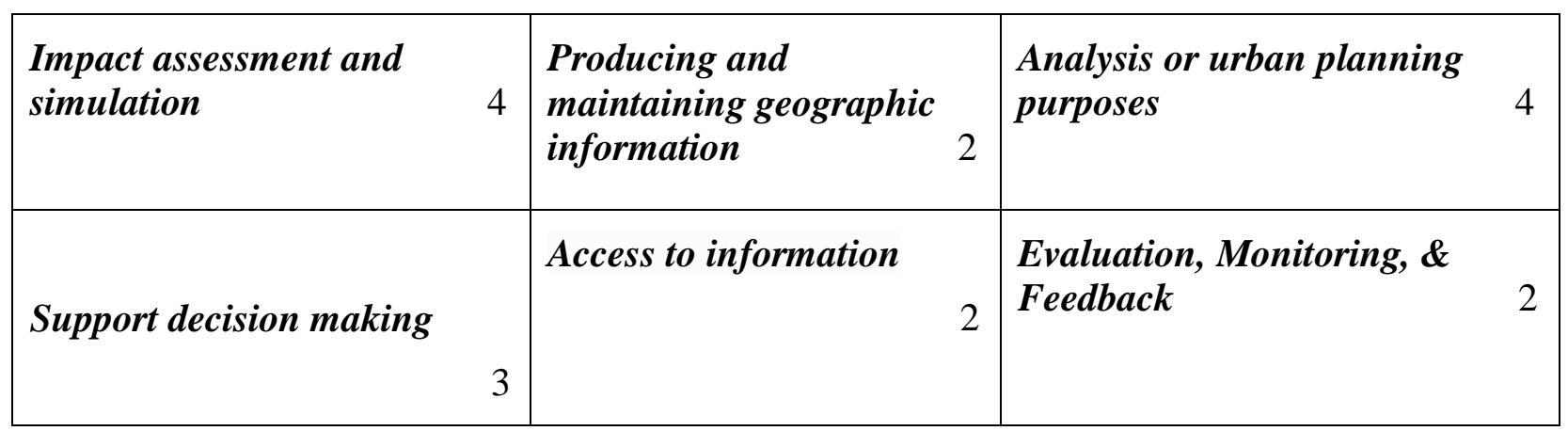

\section{Modeling of urban planning purposes}

GIS has been used in the analysis of new areas for the development of towns and cities. Most especially it has been used in identifying the buildings in terms of height and size that can be modified and modeling data with regards to the potential flooding situations in a city among others. Similarly, GIS in urban planning enables spatial analysis and modeling which contributes to a variety of important urban planning tasks. These tasks include site selection, land suitability analysis, land use and transport modeling, optimizing new building placement or determining the feasibility of a waste disposal site and the identification of planning action areas. GIS can help to 
store, manipulate, and analyze physical, social, and economic data of a city which can be used by planners through spatial query and mapping functions of GIS to analyze the existing situation in the city.

From one of the documents reviewed, it was pinpointed out that;

As a toolbox, GIS allows planners to perform spatial analysis using geoprocessing functions such as map overlay and Assists planners in identifying land use trends and developable land areas.

Similarly, another document reviewed also revealed that; GIS can be used for prediction and projection. Spatial modeling of spatial distributions makes it possible to estimate the widest range of impacts of existing trends of population, and of economic and environmental change. For example, a range of environmental scenarios can be investigated through the projection of future demand for land resources from population and economic activities, modeling of the spatial distribution of such demand, and then using GIS map overlay analysis to identify areas of conflict.

\section{Impact assessment and simulation}

With the aid of GIS, impact assessment and simulation are easily carried out by planners. Impact assessment such as environmental impact assessment are conducted to evaluate the potential effects urban development have on the environment and incase issues are found, the urban planner can recommend ways to alleviate or mitigate negative outcomes. On the same note, GIS technology empowers urban planners with enhanced visibility into data to carry out impact assessment and simulation over time, evaluate the feasibility of proposed projects and predict their effects on the environment.

GIS can be used to evaluate the impact of development on the environment to see whether adjustments of the plan are needed. GIS can also be used in the monitoring and programming of land development.

\section{Producing and maintaining geographic information}

GIS such as desktop GIS makes it easier to store, manage, and access data from a variety of sources. In addition, Cloud GIS offers that same benefit, while enabling access from any device. Similarly, in a database-oriented GIS, spatial and textual data can be stored and linked using the georelational model. It was also highlighted that GIS support efficient data retrieval, query, and mapping and planners can also extract data from their databases and input them to other modeling and spatial analysis programs.

From one of the documents reviewed, it was highlighted that; 
GIS is used for the storage of land use maps and plans, socioeconomic data, environmental data, and planning applications which are used by urban planners to extract useful information from the database through spatial query.

\section{Access to information}

GIS provides a single database where data can be stored and easily organized. Once data has been added to the database, urban planners can use spatial queries to quickly access the information. Similarly, many GIS portals can be made public facing, which means citizens can access information such as parcel outlines and information, county/district boundaries, and area zoning.

\section{Support decision making}

GIS enables speedier access to a wider ranger of important geographic information, planners can create informed strategies more effectively. More than that, they can explore a wider range of 'what-if' scenarios - ideally leading to stronger, more effective long-term strategies. In addition, Desktop GIS offers powerful mapping visualization tools, enabling planners to create maps (sometimes even in 3D). These digital maps make it easier for urban planners to make decisions and explore solutions (such as identifying an ideal location for a new park or public space).

One of the documents reviewed highlighted that;

When combined with data from other tabular databases or specially conducted surveys, geographical information can be used to make effective planning decisions.

Similarly, another document reviewed revealed that; GIS-based planning support systems allow planners and citizens to quickly and efficiently create and test alternative development scenarios and determine their likely impacts on future land use patterns and associated population and employment trends, thus allowing public officials to make informed planning decisions.

\section{Evaluation, Monitoring, \& Feedback}

From the secondary data reviewed, it was established that GIS tools can help evaluate a building plan, monitor the project after completion, and even gather feedback to help make improvements. In addition, GIS helps planners to track if development is following the area's land use plan and also evaluate impact and suggest adjustments - if required. One of the documents reviewed highlighted that;

GIS can help to monitor the environment. It can, for example, be used to monitor land use changes. It can also examine whether land development is following the land use plan of the region, by overlaying a land development map produced from the analysis of remote sensing images on the land use plan. 


\section{Conclusion}

Basing on the findings above, GIS has implications for developing strategies for urban management and planning for sustainability in the developmental process of urban areas and cites. GIS contributes significantly to urban planning and management in the following ways; it is used in the analysis of the existing situation for adequate urban planning process; it is used to produce and maintain geographical information which aids planning of urban areas and towns; GIS provides quick access of data to planners and other stakeholders which eases the urban planning and management process; it enables planners to make effective, efficient and informed decision with regards to urban planning and management; GIS enables monitoring, evaluation and provision of feedback if development is following the area's plan and also evaluate impact and suggest adjustments - if required. With regards to the aforementioned contributions of GIS towards urban planning and management, this study concludes that GIS has a positive implication on sustainable urban planning and management.

\section{Recommendations}

This study recommends that; Government of Uganda and other developing economies in the cohort of middle and low income countries as classified by world bank should develop a strong data base for the GIS system so as to enable quick access to data by planners, effective and informed decision making as strategies of stimulating economic growth and development of the economies, furthermore the researcher recommends that the usage of GIS systems should be magnified across both the local and central governments in order to foster sustainable urban planning and management in Uganda and other low and middle income economics world over.

\section{REFERENCES}

Aibinu, A. (2001). GIS Application in urban planning and urban management: Utilizing GIS in Kigali Urban planning and city management.

Bahaire, T., \& Elliot-White, M. (2010). The Application of Geographical Information Systems (GIS) in Sustainable Tourism Planning: A Review. Journal of sustainable tourism , 7 (2).

Bardon K S, Elliott C J, Stothers N (1984). Computer applications in local authority planning departments 1984: a review. Birmingham, Department of Planning and Land scape, City of Birmingham Polytechnic

Campagna, M. (2006). GIS for Sustainable development. CRC Press.

Campbell, H, J (1994). How effective are GIS in practice? A case study of British local government. International Journal of Geographical Information Systems 8: 309-25 
International Journal of Technology and Systems

ISSN 2518-881X (Online)

Vol.5, Issue 1, No.2, pp 15-27, 2021

www.iprjb.org

French, S, P., \& Wiggins, L, L (1990). California planning agency experiences with automated mapping and geographic information systems. Environment and Planning B: Planning and Design 17: 441-50

Hegazy, I.R., and Kaloop, R.M. (2015). Monitoring urban growth and land use change detection with GIS and remote sensing techniques in Daqahlia governorate Egypt. International Journal of Sustainable Built Environment, 4(1), 117-124.

Hemerijckx,L., Emelen,S.V., Rymenants,J., Davis,J., Verburg, P.H., Lwasa,S., \& Rompaey, A.V. (2020). Upscaling Household Survey Data Using Remote Sensing to Map Socioeconomic Groups in Kampala, Uganda. Remote Sens, 12, 3468.

Maarseveen, M., Martinez, J., \& Flacke, J. (2019). GIS in Sustainable Urban Planning and Management: A Global Perspective. CRC Press.

Maarseveen, M.V., Martinez, J., \& Flacke, J. (2018). GIS in Sustainable Urban Planning and Management. Boca Raton: CRC Press.

Mbabazi, J., \& Atukunda, P. K. (2020). Creation of New Cities in Uganda: Social Economic and Political Implications. Kampala: ACODE

Ministry of Lands, Housing \& Urban Development. (2017). The Uganda National Urban Policy. Kampala: MOLHUD.

Morosini, R. \&. (2019). Land use and urban sustainability assessment: A 3D-GIS application to a case study in Gozo. City, territory and architecture, 6 (7), https://doi.org/10.1186/s40410-019-0106-z.

Musinguzi, M. (2012). GIS Data interoperability in uganda. International journal of spatial data infrastructures research, 7, 488-507.

Nikuze, A., Sliuzas, R.V.,\& Flacke, J. (2018). Towards equitable urban resettlement in Kigali, Rwanda. University of Twente.

Ofori-Amoah, B. (2009). Building capacity to use geospatial technology for development in africa: lessons from the uganda gis project. Master's thesis, Western Michigan University, Department of Geography.

Pieterse, E., and Parnell, S. (2014). Africa's Urban Revolution. London: Zed Books.

Shimonti, P. (2018). Urban planning and GIS. Retrieved February 04, 2021, from https://www.geospatialworld.net/blogs/gis-in-urban-planning/ 
International Journal of Technology and Systems

ISSN 2518-881X (Online)

Vol.5, Issue 1, No.2, pp 15-27, 2021

www.iprjb.org

Sow, M. (2015, December 30). Foresight Africa 2016: Urbanization in the African context. Retrieved February 02, 2021, from https://www.brookings.edu/blog/africa-infocus/2015/12/30/foresight-africa-2016-urbanization-in-the-african-context/

UN-Habitat. (2008/9.). Global Human Settlements Report. Harmonious Cities. . London: Earthscan.

UN-Habitat,. ( 2006/7). State of the World's Cities 2006/7 The MDGs and Urban Sustainability: 30 Years of Shaping the Habitat Agenda. . London: Earthscan.

UN-Habitat,. (2006/7). State of the World's Cities 2006/7 The MDGs and Urban Sustainability: 30 Years of Shaping the Habitat Agenda. London: Earthscan.

United Nation. (2021). Goal 11: Make cities inclusive, safe, resilient and sustainable. Retrieved February 09, 2021, from https://www.un.org/sustainabledevelopment/cities/

Van de Voorde, T., Jacquet, W., \& Canters, F. (2011). Mapping form and function in urban areas: An approach based on urban metrics and continuous impervious surface data. Landscape and Urban Planning, 102(3), 143-155.

World Bank. (2012). Planning for Uganda's Urbanization. Inclusive Growth Policy Note;4. Washington, DC: World Bank.

Yeh A G-O (1991) The development and applications of geographic information systems for urban and regional planning in the developing countries. International Journal of Geographical Information Systems 5: 5-27

Appendix I: List of additional supportive materials considered in the study

\begin{tabular}{lllc}
\hline No & \multicolumn{1}{c}{ Title } & Author (s) & Year of publication \\
\hline 1 & Urban planning and GIS & Ago Yeh & 1999 \\
2 & GIS Solution for Urban planning & ESRI & 2006 \\
3 & $\begin{array}{l}\text { GIS Application in urban planning and urban } \\
\text { management: Utilizing GIS in Kigali urban } \\
\text { planning and city management }\end{array}$ & Aderemi, B & 2001 \\
4 & $\begin{array}{l}\text { GIS in sustainable Urban planning and } \\
\text { Management: A global perspective }\end{array}$ & $\begin{array}{l}\text { Taylor \& } \\
\text { Group }\end{array}$ & Francis \\
\hline
\end{tabular}


International Journal of Technology and Systems

ISSN 2518-881X (Online)

Vol.5, Issue 1, No.2, pp 15-27, 2021

www.iprjb.org

5 GIS Spatial Analysis Modeling for Land Use

Elzbieta Bielecka

2020

Change. A Bibliometric Analysis of the

Intellectual Base and Trends

6 Quantifying urban growth pattern in developing Abebe Aweke

2013

countries using remote sensing and spatial

metrics: A case study in Kampala Uganda

7 GIS support for Kampala City's Socio

Flavia zabali musisi

2013

Economic Transformation

8 Urban growth of Kampala, Uganda: Pattern

Karolien Vermeiren,

2012

analysis and scenario development

Anton Van Rompaey,

Maarten Loopmans,

Serwajja Eria

Appendix II: List of supportive web-pages visited

\begin{tabular}{cllc}
\hline No & \multicolumn{1}{c}{ Web page name } & \multicolumn{1}{c}{ Link } & Date visited \\
\hline 1 & $\begin{array}{l}\text { Utilizing GIS to Streamline Urban } \\
\text { Planning }\end{array}$ & $\begin{array}{l}\text { https://unearthlabs.com/blog/gis- } \\
\text { uses/urban-planning/ }\end{array}$ & $10 / 02 / 2021$ \\
2 & $\begin{array}{l}\text { Why GIS is Important in Urban } \\
\text { Planning }\end{array}$ & $\begin{array}{l}\text { https://gis.usc.edu/blog/why-is-gis- } \\
\text { important-in-urban-planning/ }\end{array}$ & $11 / 02 / 2021$ \\
3 & $\begin{array}{l}\text { Geographic Information Systems (GIS) } \\
\text { Section }\end{array}$ & https://www.kcca.go.ug/gis & $12 / 02 / 2021$ \\
\hline
\end{tabular}

